for the publication of articles and addresses by wellknown men of science, most of which have already appeared in previous publications such as Philosophy, Technology Review, Geographical Journal, Scientific Monthly, Report of the British Association, Science Progress, Nature, etc. This general appendix of well-chosen lectures, addresses and papers adds greatly to the value of these annual reports.

\section{The Pacific Science Congress}

THE Report for the year 1933-34 of the National Research Council of Japan contains the resolutions passed at the Fifth Pacific Science Congress held in Victoria, B.C. and Vancouver in June 1933. Steps were taken to secure more accurate information as to the depth, salinity and temperature of the ocean, the life conditions of halibut, salmon and whales in it and to prevent the discharge of oil from vessels on it. Plant diseases and parasites of the cereal crops and timber grown on the coasts and mountain ranges bordering them are to be studied more thoroughly, atmospheric circulation is to be investigated by pilot balloons, and the necessity of continuing magnetic, electric and oceanographic work by means of a new non-magnetic ship to replace the lost Carnegie was emphasised. Seismological informa. tion is to be spread by wireless as soon as it is arailable.

\section{Principles of Field Experimentation}

ThE Empire Cotton Growing Corporation has recently issued a volume of one hundred pages entitled "Prineiples and Practice of Field Experimentation", by J. Wishart and H. G. Sanders of the School of Agriculture, Cambridge. This is really the third edition of the volume, the first two, written by Engledow and Yule, having appeared in 1926 and 1930 respectively. Perhaps the most important improvements in method in the last ten years are the recognition of the usefulness of the factorial type of design, the confounding of main effects and high order interactions, the analysis of covariance and the fruits of many studies on sampling technique with cereals and root crops. Except for confounding, which is considered by the authors to be beyond the scope of the book, these topics are dealt with in this volume in a very readable manner. The section on practice contains much good advice on the planning and carrying-out of a field experiment, and is particularly welcome in that it answers many of the objections which have been raised by the so-called 'practical' man to modern methods of field experimentation.

\section{Statistical Abstract for the British Empire}

Probably the most generally useful statistical publications issued by H.M. Stationery Office are the various Statistical Abstracts, such as the Statistical Abstract for the United Kingdom, the Abstract of Labour Statistics and the Statistical Abstract for the British Empire. The sixty-fourth number of the last named has recently been published (H.M. Stationery Office, $3 s .6 d$.$) and contains a great wealth$ of statistical information relating to the exports and imports of the various Dominions, Colonies and Dependencies for each of the ten years 1925-34. It is, however, less complete than previous issues, which also included information relating to finance, production, prices, etc., but it is intended to publish the Abstract in complete form in aiternate years. Those who have frequent occasion to refer to statistical data will find this and the other Statistical Abstracts invaluable as a means of obtaining convenient summaries of official statistics drawn from very varied sources.

\section{Science Abstracts}

The issue of the index parts completes vols. 38 of Science Abstracts for 1935. The physics volume extends to 1,569 pages, 315 of which are occupied by a detailed subject index and key, and a name index. The electrical engineering volume has only 899 pages, 157 of which are index. Both are about the same size as the corresponding volumes last year. The average length of an abstract continues to be a little less than a quarter of a page, which experience seems to show is sufficient to allow an expert to give the gist of a paper, and allow a reader to keep abreast of research work in his own and kindred fields.

\section{Memorial to X-Ray Workers}

A STONE memorial to a hundred and sixty medical men, physicists, chemists, laboratory workers and nurses whose deaths were due to working with X-rays, was unveiled on April 4 at St. George's Hospital, Hamburg. The countries represented on the memorial are Germany, France, Great Britain, the United States, Italy, Hungary, Switzerland, Austria, Denmark, Czechoslovakia, Spain, Belgium, Finland, Russia and Holland. The British names inscribed are R. G. Blackall, C. R. C. Lister, Melville H. Walsham, C. Williams, E. E. Wilson, W. H. Fowler, J. S. Hall-Edwards, J. W. L. Spence, J. R. Riddell and W. I. Bruce Pirie.

\section{Announcements}

His MaJesty the King has been graciously pleased to grant his patronage to the Iron and Steel Institute. The Institute was similarly honoured by the late King George and by King Edward VII before him, both of whom had previously shown their interest in the Institute's activities by consenting to accept honorary membership. His Majesty King Edward VIII was also an honorary member until his accession to the throne.

THE Faraday Medal of the Institution of Electrical Engineers will be presented to Sir William Bragg at the ordinary meeting of the Institution to be held on Thursday, April 23, at 6 p.m. The presentation will precede the twenty-seventh Kelvin Lecture, which will be delivered by Dr. J. D. Cockcroft, on "The Transmutations of Matter by High-Energy Particles and Radiations". 